\title{
PIFA based Reconfigurable Multiband Antenna for Wireless Applications
}

\author{
Hattan F. AbuTarboush ${ }^{1}$, R. Nilavalan ${ }^{1}$ and T. Peter ${ }^{1}$
}

\begin{abstract}
A compact reconfigurable four bands Planar Inverted-F Antenna (PIFA) is presented for Digital Video Broadcasting - Handheld (DVB-H), Universal Mobile Telecommunications System (UMTS), Global System for Mobile Communications (GSM800, 900, 1800 and 1900), Personal Communications System (PCS), Wireless Local Area Network and Bluetooth (WLAN), Worldwide Interoperability for Microwave Access (m-WiMAX) and Hiperlan/2 applications. Two varactor diodes with variable capacitors are used to electrically tune the operating frequencies over a wide range. The overall size of the radiated parts is $31.5 \times 30.5 \mathrm{~mm}^{2}$ which makes it easy to integrate it into small mobile handset. Depending on the voltage applied to the switches the operating frequencies at $0.7 \mathrm{GHz}, 2 \mathrm{GHz}, 3.5 \mathrm{GHz}$ and $5 \mathrm{GHz}$ can be tuned over $30.48 \%, 20 \%, 4 \%$ and $4 \%$ respectively. The peak gains for the four bands range $-4 \mathrm{dBi}, 3 \mathrm{dBi}, 3 \mathrm{dBi}$ and $6 \mathrm{dBi}$ at DVB-H, UMTS, WiAMX and WLAN, respectively. The average efficiency of the four bands ranges from $95 \%$ to $85 \%$. The radiation patterns and other discussions are provided.
\end{abstract}

\section{INTRODUCTION}

Multiband antennas are widely being considered for future wireless communication applications. There has also been a significant interest in the field of reconfigurable antennas where the multiband capabilities can be further enhanced to incorporate multiple wireless standards. Future cognitive communication systems will require antennas capable of operating over multiple wireless standards.

Multiband Antennas are very desirable for current wireless applications as they can cover multiple frequencies using a single antenna. However, fixed multiband antenna usually requires complicated filters with inflexible requirements to improve their out-of-band noise rejection [1]. The filter usually bulky and can add complexity to any communication systems. As a solution to these disadvantages, a reconfigurable antenna can achieve a better out-ofband noise rejection. Moreover, modern wireless communication systems relying on multiband reconfigurable antennas are becoming more popular for their ability to serve multiple standards and applications using a single compact antenna allowing a reduction in the dimensions of the wireless device and more space to integrate other electronic components.

Reconfigurable antennas can be classified into three different categories. The first category is based on frequency reconfigurability. The aim is to tune the operating frequency of the antenna and to have a single multifunctional antenna in a small terminal for many applications. The second category is based on pattern reconfigurability, where the frequency band remains unchanged while the radiation pattern changes based on system requirements.

The third category is based on polarization reconfigurability, where the polarization is switched from linear to circular and from left hand (LHCP) to right hand (RHCP) circular

In the literature, different methods and techniques have been reported recently to achieve reconfigurable performance. For examples a tunable antenna using PIN switches was reported in [2] and [3]. A method to reconfigure the operating frequencies is introduced in [4] for multiband wireless applications by switching different feeding location of the antenna. Wideband can be achieved by switching ON and OFF 2 patches [2]. Tuning dual-band PIFA is achieved by using varator diodes [5]. Also by using PIN diode [6] or by using PIN diode and Varactor diode [7]. The radiation patterns of these reported antennas remain unchanged when the frequencies are tuned from one band to the other. There are different kinds of switching technologies that can be used to achieve reconfigurability, such as optical switches, PIN diodes, FETs, and radio frequency microelectromechanical system (RF-MEMS) switches [8]. Varactor diodes is the most commonly used to tune the operating frequencies in RF and front-end application.

This paper will look into reconfigurable four bands antenna and present some work carried out on a PIFA based antenna [9]. The proposed design generates four bands to serve DVB-H, UMTS, WiMAX and WLAN applications. These bands can be tuned to other set of frequencies by changing the capacitance of the varactor diodes.

\footnotetext{
${ }^{1}$ Wireless Networks\&Communications Centre (WNCC), School of Engineering and Design, Brunel University, West London UB8 3PH, UK e-mail: Rajagopal.Nilavalan@brunel.ac.uk
} 


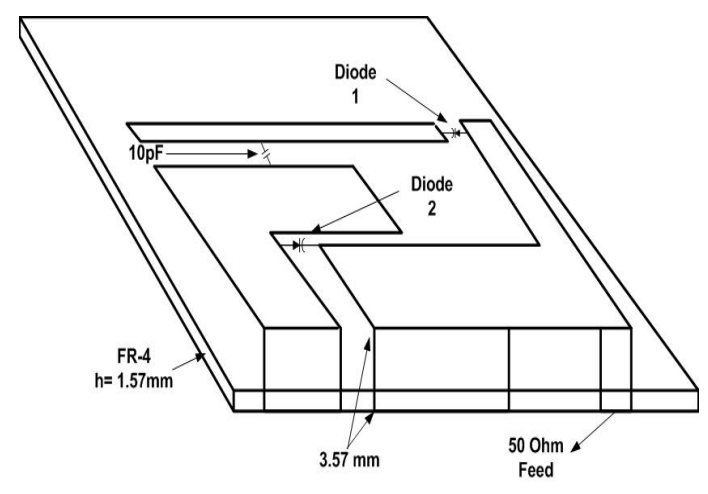

(a)

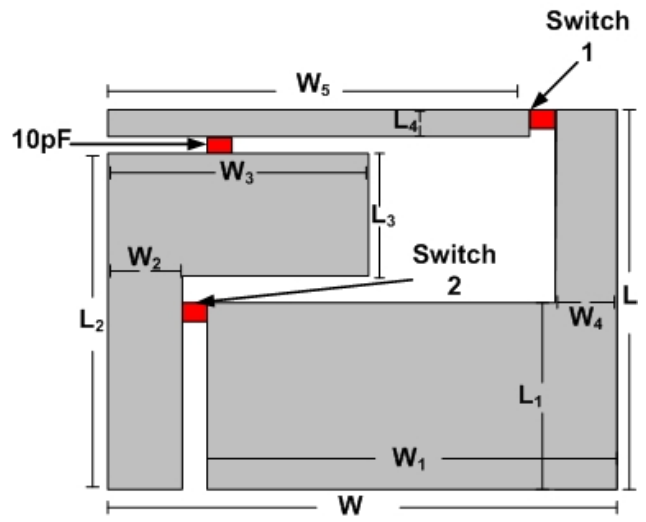

(b)

Figure 1 Structure of the antenna (a) 3D (b) Top view

\begin{tabular}{|c|c|c|c|c|c|}
\hline $\boldsymbol{L}$ & $\boldsymbol{L}_{\boldsymbol{1}}$ & $\boldsymbol{L}_{\mathbf{2}}$ & $\boldsymbol{L}_{3}$ & $\boldsymbol{L}_{\boldsymbol{4}}$ & $\boldsymbol{h}$ \\
\hline 30.5 & 11.5 & 25 & 12 & 5 & 1.57 \\
\hline $\boldsymbol{W}$ & $\boldsymbol{W}_{\boldsymbol{1}}$ & $\boldsymbol{W}_{\mathbf{2}}$ & $\boldsymbol{W}_{\mathbf{3}}$ & $\boldsymbol{W}_{\boldsymbol{4}}$ & $\boldsymbol{W}_{\boldsymbol{5}}$ \\
\hline 31.5 & 23.5 & 7 & 15 & 6 & 25.5 \\
\hline
\end{tabular}

Table I: Dimensions of the proposed antenna

\begin{tabular}{|c|c|c|c|c|}
\hline Frequency (GHz) & $0.70-0.95$ & $1.79-2.19$ & $3.43-3.57$ & $4.95-5.2$ \\
\hline Tuning Rang & $30.48 \%$ & $20 \%$ & $4 \%$ & $4 \%$ \\
\hline
\end{tabular}

Table II: The achieved maximuam tuning range for the four bands

\section{DESIGN PROCEDURE AND RESULTS}

\section{A. Structure and Specifications of the Proposed Antenna}

The work presented in this paper continues further investigation on the design of multiband small antenna that reported in [9]. The structure of the proposed reconfigurable PIFA is shown in Figure 1(a)-(b) and the dimensions are listed in Table I. Slots were created in the structure to excite multiple resonances in the antenna as described in the earlier results [9]. The antenna is designed with an area of $43.6 \times 50 \mathrm{~mm}^{2}$. It consists of two varactor-diode switches and a $10 \mathrm{pF}$ capacitor. The antenna is designed on a $1.57 \mathrm{~mm}$-thick FR-4 substrate with a dielectric constant of 4.4 and loss tangent $=0.02$.

The varactor diode is a semiconductor diode with a small junction capacitance that varies its value depending on the bias voltage applied to the diode.

The varactor diodes selected for the design is a BB184 from NXP with a capacitance value ranging from $2 \mathrm{pF}$ to $14 \mathrm{pF}$ controlled by a DC bias voltage varying from $1 \mathrm{~V}$ to $14 \mathrm{~V}$. The dimension of the varactor diodes is approximately $1 \times 1 \mathrm{~mm}^{2}$.

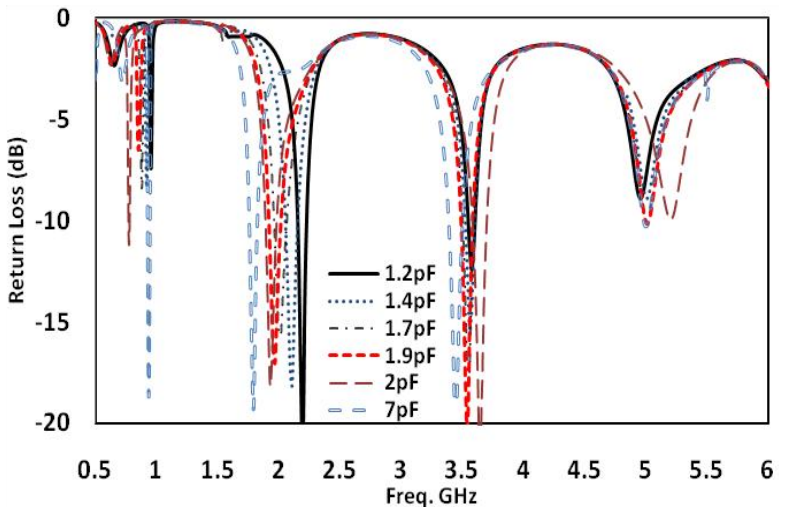

Figure 2 Return Loss with varactor diodes

The location of attaching the varactor diode was optimized using HFSS electromagnetic full-wave simulator software version 11.2. In the simulations, the varactor diode was modeled with an RLC boundary. The proposed reconfigurable antenna can be tuned to operate at the frequency bands used by DVB-H, GSM800, GSM900, GSM1900, PCS, UMTS, 


\begin{tabular}{|c|c|c|c|c|}
\hline Cp & \multicolumn{4}{|c|}{ Applications } \\
\hline \multirow{2}{*}{$1.2 \mathrm{pF}$} & GSM900 & UMTS & WiMAX & HiperLAN/2 \\
\hline & 0.95 & 2.19 & 3.57 & 5.06 \\
\hline \multirow{2}{*}{$1.4 \mathrm{pF}$} & GSM900 & UMTS & WiMAX & HiperLAN/2 \\
\hline & 0.91 & 2.10 & 3.55 & 5.03 \\
\hline \multirow{2}{*}{$1.7 \mathrm{pF}$} & GSM800 & UMTS & WiMAX & HiperLAN/2 \\
\hline & 0.85 & 2.00 & 3.52 & 5 \\
\hline \multirow{2}{*}{$1.9 \mathrm{pF}$} & GSM800 & GSM1900 & WiMAX & HiperLAN/2 \\
\hline & 0.80 & 1.96 & 3.50 & 5 \\
\hline \multirow{2}{*}{$2 \mathrm{pF}$} & DVB-H & GSM1900 & WiMAX & WLAN \\
\hline & 0.70 & 1.90 & 3.64 & 5.2 \\
\hline \multirow{2}{*}{$7 \mathrm{pF}$} & GSM900 & PCS & WiMAX & HiperLAN/2 \\
\hline & 0.93 & 1.79 & 3.43 & 5 \\
\hline
\end{tabular}

Table III: Operating Frequencies of the antenna when both varactor diodes are changed simultaneously

WiMAX and HiperLAN/2, reducing antenna redundancy.

\section{B. Results and Discussions}

The reflection coefficients $\left(\mathrm{S}_{11}\right.$ in $\left.\mathrm{dB}\right)$ of the proposed antenna for different varactor bias voltages are presented in Figure 2. The arrangements of the slots allowed the antenna to generate four bands. These four bands are able to be tuned over wide range to cover other set of frequencies without changing the physical size of the antenna. The varactor diodes selected for the design has a capacitance value ranging from $2 \mathrm{pF}$ to $14 \mathrm{pF}$ controlled by a DC bias voltage. Depending on the capacitance value of the switches supplied to both varactors simultaneously, the four bands can be tuned over a wide range. For example if the capacitance of the diode is set at $2 \mathrm{pF}$, the four bands can operates at $0.7 \mathrm{GHz}$ for DVB-H applications, $1.90 \mathrm{GHz}$ for GSM1900 applications, $3.50 \mathrm{GHz}$ for WiMAX applications and $5.2 \mathrm{GHz}$ WLAN applications. The four bands can be tuned between $(0.70$ to $0.95 \mathrm{GHz})$ for the first band, $(1.79$ to $2.19 \mathrm{GHz})$ for the second band, (3.43 to $3.57 \mathrm{GHz})$ for the third band and (4.95 to $5.2 \mathrm{GHz})$ as shown in Table II. This allows the antenna to be used to service most of the existed wireless applications.

The radiation patterns for the four bands when the varactor diodes is at $1.7 \mathrm{pF}$ are shown in Figure 3(a)(d). The gain for the $0.88 \mathrm{GHz}, 2 \mathrm{GHz}, 3.55 \mathrm{GHz}$ and $5 \mathrm{GHz}$ are $-4 \mathrm{dBi}, 3 \mathrm{dBi}, 4 \mathrm{dBi}$ and $6 \mathrm{dBi}$ respectivily as shown in Figure 4.
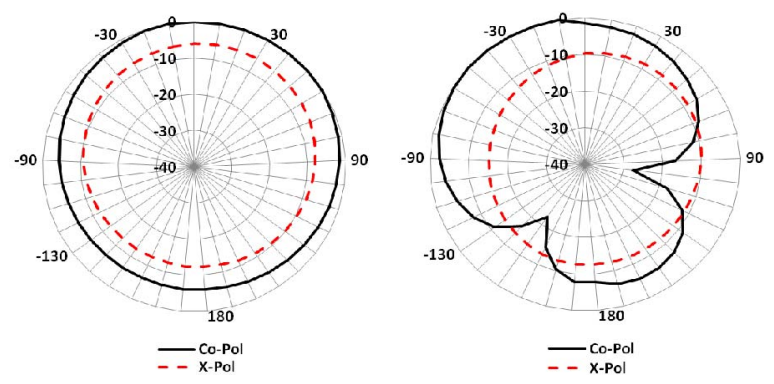

(a)
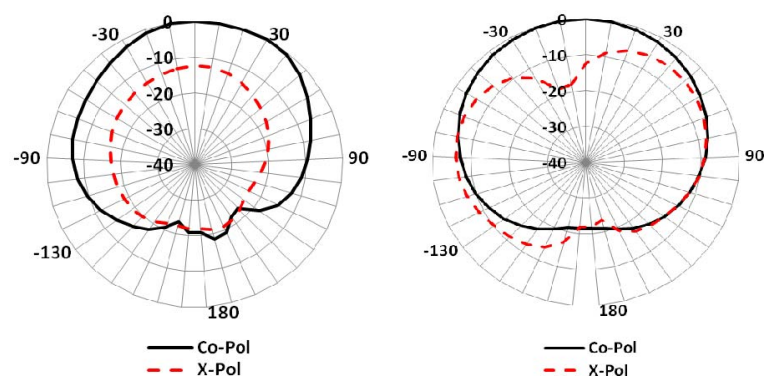

(b)
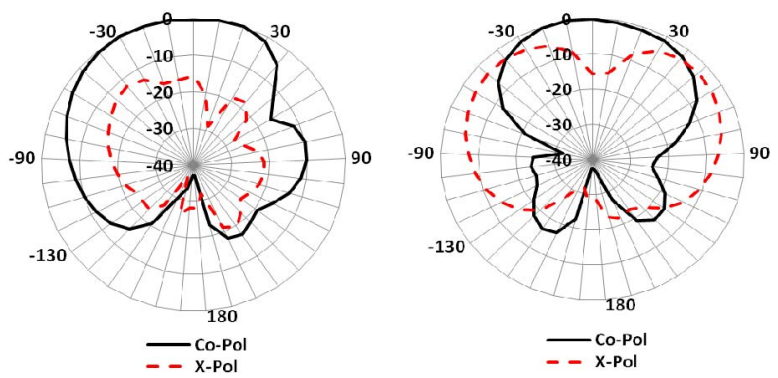

(c) 


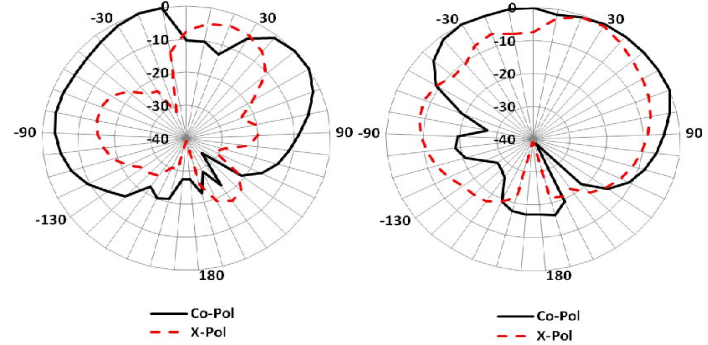

(d)

Figure $3 \mathrm{Co}-\mathrm{Pol}$ and X-Pol for E-Plane and H-Plane at (a) $0.88 \mathrm{GHz}$ (b) $2 \mathrm{GHz}$ (c) $3.55 \mathrm{GHz}$ and (d) $5 \mathrm{GHz}$

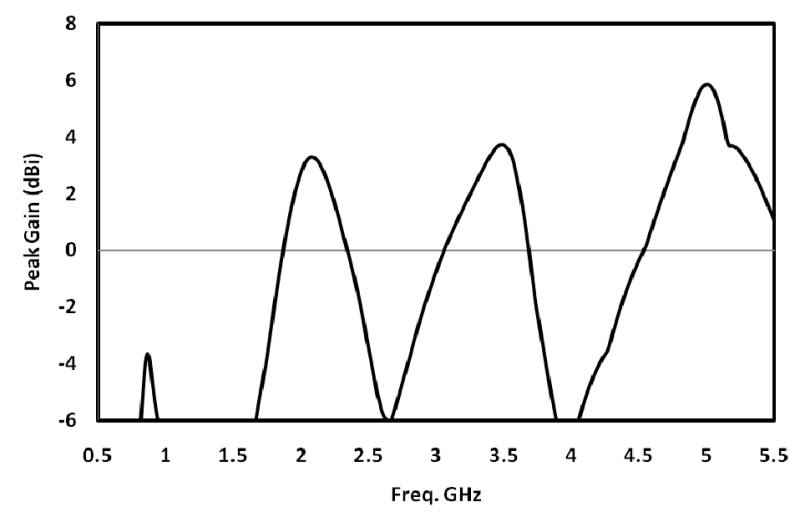

Figure 4 Simulated peak gain for the four bands

\section{CONCLUSION}

A compact PIFA design has been proposed using two varactor diodes. The proposed antenna was able to generate four bands. Depending on the voltage applied to the varactors, the four bands can cover the DVB-H, GSM800, GSM900, PCS, GSM1800, GSM1900, UMTS, WLAN/Bluetooth, m-WiMAX and $5 \mathrm{GHz}$ WLAN bands. Radiation patterns and gain showed that the four bands can serve the mentioned services with good performance.

\section{References}

[1] S. Yang, C. Zhang, H. Pan, A. Fathy and V. Nair, "Frequency-reconfigurable antennas for multiradio wireless platforms," IEEE Microwave Magazine, vol. 10, pp. 66-83, 2009.

[2] H. F. AbuTarboush, R. Nilavalan, H. S. AlRaweshidy and D. Budimir, "Reconfigurable Dual-band and Wideband Antenna for Cognitive Radio Applications," Antennas and Propagation Conference, Loughborough, LAPC 2009.

[3] A. Sheta and S. F. Mahmoud, "A Widely Tunable Compact Patch Antenna," IEEE
Antennas and Wireless Propagation Letters, vol. 7, pp.40-42, 2008.

[4] A. C. K. Mak, C. R. Rowell, R. D. Murch and Chi-Lun Mak, "Reconfigurable Multiband Antenna Designs for Wireless Communication Devices," IEEE Transactions on Antennas and Propagation, vol. 55, pp. 1919-1928, 2007.

[5] Luyi Liu; Langley, R., "Electrically small antenna tuning techniques," Antennas \& Propagation Conference, 2009. LAPC 2009. Loughborough , vol., no., pp.313-316, 16-17 Nov. 2009

[6] Yue Li; Zhijun Zhang; Wenhua Chen; Zhenghe Feng; Iskander, M.F.; , "A Quadband Antenna With Reconfigurable Feedings," IEEE Antennas and Wireless Propagation Letters, vol.8, no., pp.1069-1071, 2009

[7] Lim, J.-H.; Back, G.-T.; Ko, Y.-I.; Song, C.W.; Yun, T.-Y.; , "A Reconfigurable PIFA Using a Switchable PIN-Diode and a FineTuning Varactor for USPCS/WCDMA/mWiMAX/WLAN," Antennas and Propagation, IEEE Transactions on , vol.PP, no.99, pp.1-1, 2010

[8] M. Spasos, N. Charalampidis, N. Mallios, D. Kampitaki, K. Tsiakmakis, P. Tsivos Soel and R. Nilavalan, On the Design of an Ohmic RF MEMS Switch for Reconfigurable Microstrip Antenna Applications, WSEAS Transactions On Communications, Issue 1, Vol. 8, Jan 2009

[9] Hattan F. AbuTarboush, R. Nilavalan, H. S. Al-Raweshidy and D. Budimir, "Design of planar inverted-F antennas (PIFA) for multiband wireless applications," International Conference on Electromagnetics in Advanced Applications, 2009. ICEAA '09, pp.78-81, 2009. 